\title{
Venous thromboembolism and intracranial hemorrhage after craniotomy for primary malignant brain tumors: a National Surgical Quality Improvement Program analysis
}

\author{
Joeky T. Senders ${ }^{1,2} \cdot$ Nicole H. Goldhaber $^{1} \cdot$ David J. Cote $^{1} \cdot$ Ivo S. Muskens $^{1,2}$ \\ Hassan Y. Dawood ${ }^{1}$ - Filip Y. F. L. De Vos $^{3}$ • William B. Gormley ${ }^{1}$. \\ Timothy R. Smith ${ }^{1} \cdot$ Marike L. D. Broekman $^{1,2}$ (1)
}

Received: 12 July 2017 / Accepted: 29 September 2017 / Published online: 16 October 2017

(C) The Author(s) 2017. This article is an open access publication

\begin{abstract}
Venous thromboembolism (VTE), including deep venous thrombosis (DVT) and pulmonary embolism (PE), frequently complicates the postoperative course of primary malignant brain tumor patients. Thromboprophylactic anticoagulation is commonly used to prevent VTE at the risk of intracranial hemorrhage (ICH). We extracted all patients who underwent craniotomy for a primary malignant brain tumor from the National Surgical Quality Improvement Program (NSQIP) registry (2005-2015) to perform a time-to-event analysis and identify relevant predictors of DVT, PE, and ICH within 30 days after surgery. Among the 7376 identified patients, the complication rates were 2.6, 1.5 , and $1.3 \%$ for DVT, PE, and ICH, respectively. VTE was the second-most common major complication and thirdmost common reason for readmission. ICH was the most common reason for reoperation. The increased risk of VTE extends beyond the period of hospitalization, especially for $\mathrm{PE}$, whereas ICH occurred predominantly within the first days after surgery. Older age and higher BMI were overall predictors of VTE. Dependent functional status and longer
\end{abstract}

Timothy R. Smith and Marike L. D. Broekman have shared last author.

Marike L. D. Broekman

m.l.d.broekman-4@umcutrecht.nl

1 Computational Neurosciences Outcomes Center, Department of Neurosurgery, Brigham and Women's Hospital, Harvard Medical School, 60 Fenwood Road, Boston, MA 02115, USA

2 Department of Neurosurgery, University Medical Center Utrecht, Heidelberglaan 100, 3584 CX Utrecht, The Netherlands

3 Department of Medical Oncology, University Medical Center Utrecht, Heidelberglaan 100, 3584 CX Utrecht, The Netherlands operative times were predictive for VTE during hospitalization, but not for post-discharge events. Admission two or more days before surgery was predictive for DVT, but not for PE. Preoperative steroid usage and male gender were predictive for post-discharge DVT and PE, respectively. ICH was associated with various comorbidities and longer operative times. This multicenter study demonstrates distinct critical time periods for the development of thrombotic and hemorrhagic events after craniotomy. Furthermore, the VTE risk profile depends on the type of VTE (DVT vs. PE) and clinical setting (hospitalized vs. post-discharge patients).

Keywords Deep venous thrombosis - Intracranial hemorrhage $\cdot$ Primary malignant brain tumor $\cdot$ Pulmonary embolism $\cdot$ Venous thromboembolism

\section{Introduction}

Venous thromboembolism (VTE), including deep venous thrombosis (DVT) and pulmonary embolism (PE), is a major cause of morbidity and mortality in patients undergoing craniotomy for primary malignant brain tumors [1-6]. In addition to known surgical risk factors, such as venous stasis from perioperative immobility, endothelial injury, and inflammation from the operation itself, cancer is a recognized risk factor for VTE development [7]. Among all cancer types, high-grade gliomas have been shown to result in second highest lifetime risk for cancer-related VTE, one of the highest risks of perioperative VTE and, when comparing craniotomy for any brain tumor to craniotomy for non-neoplastic disease, rates of postoperative VTE have been reported to be twice as high [8-11]. VTE has been reported as one of the most frequent major complications after craniotomy for brain tumors with incidences up to $21 \%$ in the first 3 months after surgery [1-6]. 
Previous studies have identified older age, male sex, Hispanic ethnicity, history of craniotomy, history of VTE, congestive heart failure, coagulopathy, seizures, increased stay on the intensive care unit, prolonged hospital stay, medium bed size, residual tumor tissue, and absence of thromboprophylactic therapy as predictors of VTE after craniotomy for primary malignant brain tumors [3, 4, 6, 12-15]. Most of these studies have been small, single-center studies, and none of these studies have identified predictors or performed time-to-event analyses separated for VTE type (DVT vs. PE) and the clinical setting (hospitalized vs. post-discharge patients).

Most patients undergoing surgery for brain tumors receive pharmaceutic prophylaxis in combination with mechanical prophylaxis in the perioperative setting [16-19]. However, anticoagulation increases the risk of intracranial hemorrhage (ICH), which is one of the most frequent and feared complications in patients undergoing operations for brain tumors [20]. The increased risk of ICH makes the use of prophylactic anticoagulation an issue of great debate and careful balance in this patient population. Although the incidence of ICH is lower compared to VTE events, their outcomes can be at least as detrimental. Only few predictors associated with ICH have been identified including history of craniotomy, use of bevacizumab, and therapeutic anticoagulation for a VTE [13, 20-24]. Adequate assessment of the perioperative risk of both VTE and ICH among this patient population, as well as accurately predicting the typical time to a thrombotic or hemorrhagic event, is meaningful in tailoring postoperative management to the risk profile of the individual patient.

The American College of Surgeons (ACS) National Surgical Quality Improvement Program (NSQIP) database registers follow-up of neurosurgical patients for 30 days postoperatively, and reports variables relevant to this issue, including the occurrence of DVT, PE, and $\mathrm{ICH}$ with related time-to-event data. Because the risk of $\mathrm{ICH}$ is intimately tied to the thromboprophylactic treatment used for patients with brain tumors, this study addresses thrombotic as well as hemorrhagic complications. In this study, NSQIP was used to identify predictors and perform time-to-event analyses for VTE and ICH. Assessment of VTE was stratified for VTE type (DVT vs. PE) and clinical setting (hospitalized vs. postdischarge patients).

\section{Methods}

\section{Data source}

The NSQIP includes surgical patients from over 600 participating hospitals in the U.S. operated on from 2005 to 2015. This validated dataset is collected by trained surgical reviewers using a standardized protocol, and includes common postoperative complications, occurrence of reoperations and readmissions, together with associated reasons and time-to-event in days. The NSQIP registry has previously been used to study outcomes after neurosurgical procedures [25-36]. Our institutional review board has exempted the NSQIP database from review.

\section{Inclusion criteria}

Patients were included who met the following criteria: (1) age 18 years or older; (2) a Current Procedural Terminology (CPT) code indicating craniotomy for surgical resection of brain tumor (CPT: 61500, 61510, 61512, 61518, 61519, $61520,61521,61526$, and 61530); (3) a postoperative diagnosis indicative of primary malignant brain tumor (International Classification of Diseases, Ninth Revision [ICD-9]: 191.x).

\section{Covariates}

Age, body mass index (BMI), and operative time were assessed continuously in years, $\mathrm{kg} / \mathrm{m}^{2}$, and minutes, respectively. Other categorized pre- and perioperative covariates included sex, race, American Society of Anesthesiologists (ASA)-classification (I-II, III or IV-V), functional status (dependent or independent), smoking within 1 year prior to surgery, history of hypertension requiring medication, chronic heart failure, COPD, renal failure, dialysis, insulin dependent diabetes, bleeding disorder, weight loss $(>10 \%$ loss of body weight in the 6 months prior to surgery), dyspnea, ventilator dependence, steroid usage, emergency classification, transfer status (admitted from home vs. not from home), creatinine ( $<1.4$ vs. $\geq 1.4 \mathrm{mg} / \mathrm{dL})$, hematocrit $(<36$ vs. $\geq 36 \%)$, platelet count $\left(100-450 / \mu \mathrm{m}^{3},<100 / \mu \mathrm{m}^{3}\right.$, vs. $\left.>450 / \mu^{3}\right)$, sodium $(135-145 \mathrm{mEq} / \mathrm{L},<135 \mathrm{mEq} / \mathrm{L}$, vs. $>145 \mathrm{mEq} / \mathrm{L})$, white blood cell (WBC) count $(\leq 12,000 /$ $\mu \mathrm{L}$ vs. $>12,000 / \mu \mathrm{L})$, preoperative transfusion, preoperative systemic inflammatory response syndrome, admission two or more days before surgery, and anesthesia type (general vs. no general anesthesia).

\section{Missing data}

Covariates with more than $10 \%$ missing data or occurring in less than $1 \%$ of cases were excluded from multivariable analysis. Cases with missing data in one of the variables of the multivariable analysis were excluded from the analysis. A confirmatory analysis was performed for every multivariable model, in which missing data was coded as an additional group to verify if missing data affected the results. 


\section{Outcomes}

VTE was defined as the occurrence of DVT or PE within 30 days after surgery. The occurrence of other major complications and reasons for readmission and reoperation were extracted by means of ICD-9 and CPT codes, to assess the relative contribution of VTE and ICH to morbidity, readmission, and reoperation. Based on a previously published definition, major complications were defined as either acute renal failure, cardiac arrest, death, failure to wean from ventilator, myocardial infarction, reintubation, reoperation, stroke, VTE, sepsis, and surgical site infection [37]. ICH was defined as the occurrence of an $\mathrm{ICH}$ requiring surgical evacuation and extracted by means of CPT and ICD-9 codes. Reasons for reoperation including ICH were collected since 2012.

\section{Statistical analysis}

Statistical analyses were conducted using R 3.3.3 (R Core Team, Auckland, New Zealand). Univariable analysis was performed using logistic regression. Each primary thrombotic outcome (VTE, DVT, PE) was assessed for its occurrence during the initial hospital stay, after discharge, and within 30 days overall. ICH was assessed within 30 days overall. Potential predictors were selected for inclusion in the multivariable logistic regression analysis based on univariable analysis for each outcome. Only pre- and intraoperative factors were included in the multivariable analysis, because inclusion of postoperative complications other than VTE or ICH would reduce the timeframe in which complications can be detected due to the limited 30-day collection timeframe of NSQIP, thereby biasing the results of the model. Potential predictors were excluded from the final model if they demonstrated multicollinearity or had a relative low contribution to model fit. A p value below 0.05 was considered statistically significant. Bonferroni correction for multiple testing was deemed to be too rigorous due to the low number of events. The $\beta$-coefficients of the continuous variables in the final model were multiplied to represent the odds ratios and confidence intervals of meaningful and interpretable units for age (per 10 years increase), BMI (per $5 \mathrm{~kg} / \mathrm{m}^{2}$ increase), and operative time (per $60 \mathrm{~min}$ increase).

\section{Results}

\section{Demographics of study population}

The NSQIP registry provided 7376 patients who underwent craniotomy for resection of a primary malignant brain tumor during the study period. Comorbidities, demographics, and preoperative laboratory values are shown separated by the occurrence of VTE (Table 1).

\section{Outcomes}

Of the 7376 patients that were identified, 257 (3.5\%) developed a VTE within 30 days after surgery, of which 91 (36\%) occurred within the initial hospital stay. VTE was the second-most common major complication and included 192 DVTs (2.6\%) and 107 PEs (1.5\%). Forty-two patients developed both DVT and PE $(0.6 \%)$. The rate of DVT was highest within the first 2 weeks after surgery, whereas the rate of PE was fairly consistent throughout the first month, occurring predominantly post-discharge (Fig. 1a, b). The rate of VTE was more than twice as high (7.0 vs. $3.2 \%$, $\mathrm{p}<0.001$ ) among patients with a preoperative dependent functional status compared to patients with an independent functional status (Fig. 1c).

The median length of stay among VTE patients was 8 days (inter-quartile range [IQR] 5-16 days) compared to 4 days (IQR 3-8 days) in non-VTE patients (Fig. 1d). Inhospital VTE occurred at a median of 6 days (IQR 3-8 days) after surgery, and patients were discharged at a median of 8 days after the occurrence of VTE (IQR 3-16 days). Postdischarge VTE occurred at a median of 13 days after discharge (IQR 6-19 days) and resulted in 25\% of cases in readmission, making VTE the third-most common reason for readmission (7.4\% of total readmissions). Of the patients that developed a PE, 35 (32.7\%) were preceded by a DVT. Post-discharge PEs were less frequently preceded by a DVT than hospital acquired PEs (26 vs. $48 \%, p=0.048$ ).

Of the 5699 patients that were identified in the NSQIP registry 2012-2015 with data on reoperation and associated reasons, $72(1.3 \%)$ developed an ICH requiring surgical evacuation at a median of 2 days after surgery (IQR 0-7.5 days) (Fig. 1e). ICH was the most common reason for reoperation (18.5\% of the total number of reoperations). The median length of stay among ICH patients was 12 days (IQR 6-21 days) compared to 4 days (IQR 3-8 days) in non-ICH patients (Fig. 1f). The 55 patients (77.5\%) that developed an ICH during the initial hospital stay, were discharged at a median of 10 days (IQR 6-19) after the occurrence of ICH.

\section{Multivariable analysis}

Older age and higher BMI were found to be risk factors of VTE overall (Tables 2, 3). Dependent functional status and longer operative times were predictive for hospital VTE, but not for post-discharge events. Admission two or more days before surgery was a predictor of DVT, but not for PE. Steroid usage was predictive for post-discharge DVT, and male gender was predictive for post-discharge PE. Higher 
Table 1 Demographics and preoperative comorbidities of NSQIP patients undergoing craniotomy for glioma, compared by VTE occurrence

\begin{tabular}{|c|c|c|c|c|c|c|c|}
\hline Characteristic (\%) & Definition & $\begin{array}{l}\text { Total } \\
(\mathrm{n}=7376)\end{array}$ & $\begin{array}{l}\text { No VTE } \\
(\mathrm{n}=7119)\end{array}$ & $\begin{array}{l}\text { VTE } \\
(\mathrm{n}=257)\end{array}$ & Odd ratio & $95 \% \mathrm{CI}$ & $\mathrm{p}$ value \\
\hline Age & Years \pm SD & $54.5 \pm 15.6$ & $54.4 \pm 15.6$ & $59.4 \pm 15.7$ & $1.25^{\mathrm{a}}$ & $1.15-1.36$ & $<0.001$ \\
\hline \multirow[t]{2}{*}{ Gender } & Female & 42.3 & 42.3 & 41.6 & Ref & - & - \\
\hline & Male & 57.7 & 57.7 & 58.4 & 1.03 & $0.91-1.19$ & 0.82 \\
\hline \multirow[t]{4}{*}{ Race } & White & 91.7 & 91.7 & 94.8 & Ref & - & - \\
\hline & Black & 4.8 & 4.8 & 4.2 & 0.85 & $0.40-1.60$ & 0.66 \\
\hline & Asian & 3.0 & 3.0 & 0.5 & 0.15 & $0.01-0.67$ & 0.04 \\
\hline & Other & 0.5 & 0.5 & 0.5 & 0.95 & $0.05-4.51$ & 0.96 \\
\hline \multirow[t]{3}{*}{ ASA Classification } & I-II & 27.7 & 28.1 & 18.3 & Ref & - & - \\
\hline & III & 59.2 & 59.0 & 65.5 & 1.71 & $1.23-2.40$ & 0.002 \\
\hline & IV-V & 13.0 & 12.9 & 16.3 & 1.94 & $1.26-2.97$ & 0.002 \\
\hline BMI & $\mathrm{kg} / \mathrm{m}^{2} \pm \mathrm{SD}$ & $28.4 \pm 6.2$ & $28.4 \pm 6.2$ & $29.8 \pm 6.3$ & $1.19^{\mathrm{b}}$ & $1.08-1.30$ & $<0.001$ \\
\hline Smoking & & 17.1 & 17.4 & 10.1 & 0.53 & $0.35-0.78$ & 0.003 \\
\hline Emergency case & & 6.5 & 6.5 & 8.9 & 1.42 & $0.89-2.15$ & 0.12 \\
\hline Admitted not from home & & 18.1 & 18.4 & 24.2 & 1.42 & $1.05-1.89$ & 0.02 \\
\hline Hypertension & & 35.4 & 35.1 & 43.6 & 1.43 & $1.11-1.83$ & 0.006 \\
\hline History of COPD & & 2.4 & 2.3 & 3.1 & 1.35 & $0.60-2.59$ & 0.42 \\
\hline History of CHF & & 0.2 & 0.2 & 0.8 & 3.48 & $0.55-12.32$ & 0.10 \\
\hline Renal Failure & & 0.1 & 0.1 & 0.4 & 4.63 & $0.24-27.24$ & 0.16 \\
\hline Dialysis & & 0.1 & 0.1 & 0.0 & Inf. $^{d}$ & Inf. $^{d}$ & 1.000 \\
\hline Ventilator dependence & & 1.1 & 1.1 & 3.1 & 2.98 & $1.31-5.86$ & 0.004 \\
\hline Weight loss & & 1.7 & 1.7 & 1.6 & 0.93 & $0.28-2.23$ & 0.89 \\
\hline Bleeding disorder & & 2.2 & 2.1 & 3.1 & 1.46 & $0.65-2.82$ & 0.30 \\
\hline Dyspnea & & 2.6 & 2.6 & 2.7 & 1.07 & $0.45-2.12$ & 0.87 \\
\hline Insulin-dependent diabetes & & 3.9 & 3.8 & 4.7 & 1.23 & $0.65-2.13$ & 0.49 \\
\hline Preoperative steroid usage & & 16.6 & 16.4 & 23.3 & 1.55 & $1.15-2.07$ & 0.004 \\
\hline Dependent functional status & & 5.1 & 5.0 & 10.4 & 2.23 & $1.43-3.32$ & $<0.001$ \\
\hline Preoperative SIRS & & 3.6 & 3.4 & 5.1 & 1.51 & $0.81-2.56$ & 0.16 \\
\hline Preoperative transfusion & & 0.2 & 0.2 & 0.4 & 1.85 & $0.10-9.18$ & 0.55 \\
\hline \multirow[t]{3}{*}{ Preoperative Sodium } & $135-145$ & 89.9 & 90.0 & 87.2 & Ref & - & - \\
\hline & $<135$ & 9.1 & 9.0 & 10.8 & 1.24 & $0.80-1.83$ & 0.31 \\
\hline & $>145$ & 1.0 & 1.0 & 2.0 & 2.07 & $0.72-4.69$ & 0.12 \\
\hline Preoperative creatinine & $\geq 1.4 \mathrm{mg} / \mathrm{dL}$ & 4.4 & 4.6 & 4.4 & 0.96 & $0.49-1.69$ & 0.90 \\
\hline Preoperative WBC & $>12,000 / \mu \mathrm{L}$ & 24.8 & 24.4 & 33.1 & 1.53 & $1.16-1.99$ & 0.002 \\
\hline Preoperative Hematocrit & $<36 \%$ & 11.9 & 11.8 & 12.6 & 1.07 & $0.72-1.54$ & 0.71 \\
\hline \multirow[t]{3}{*}{ Platelets } & $100-450$ & 97.5 & 97.6 & 95.7 & Ref & - & - \\
\hline & $<100$ & 1.3 & 1.0 & 2.8 & 2.29 & $0.95-4.65$ & 0.05 \\
\hline & $>450$ & 1.2 & 1.2 & 1.6 & 1.37 & $0.41-3.33$ & 0.54 \\
\hline Operative time & Minutes [IQR] & $179[123-250]$ & $179[123-250]$ & 191 [134-252] & $1.33^{\mathrm{c}}$ & $1.02-1.74$ & 0.04 \\
\hline No general anesthesia & & 5.9 & 5.9 & 5.4 & 0.91 & $0.50-1.52$ & 0.74 \\
\hline Admission to operation & $\geq 2$ days & 32.8 & 32.4 & 46.3 & 1.80 & $1.40-2.31$ & $<0.001$ \\
\hline
\end{tabular}

Bold p-values below 0.05 were considered as statistically significant

ASA American Society of Anesthesiologists, $C I$ confidence interval, $C H F$ congestive heart failure, SIRS systematic inflammatory response syndrome, $W B C$ white blood cell count

${ }^{a}$ Inflated $\beta$-coefficients to odds ratio per 10 years increase

${ }^{\mathrm{b}}$ Inflated $\beta$-coefficients to odds ratio per $5 \mathrm{~kg} / \mathrm{m}^{2}$ increase

${ }^{\mathrm{c}}$ Inflated $\beta$-coefficients to odds ratio per $60 \mathrm{~min}$ increase

${ }^{\mathrm{d}}$ Infinity due to 0 count in one of the cells 

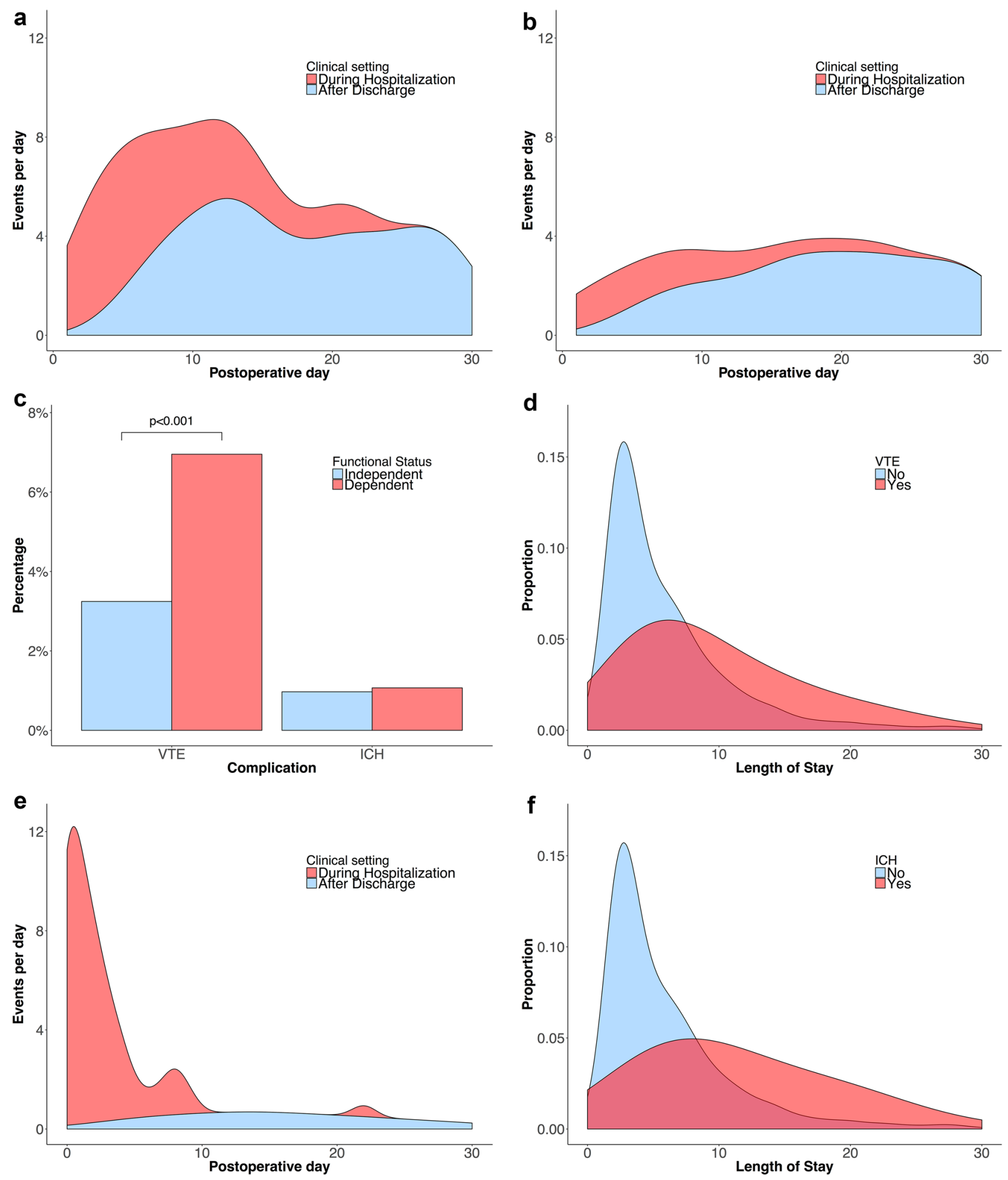

Fig. 1 Number of patients per day in the total population developing a deep venous thrombosis (a), pulmonary embolism (b) or intracranial hemorrhage (e) after craniotomy stratified for timing of

diagnosis. Distribution of length of postoperative stay compared by the occurrence of VTE (d) and ICH (f). Frequency of VTE and ICH compared by functional status (c) 
Table 2 Multivariable analysis comparing risk profiles for DVT occurring in-hospital $(n=69)$ versus post-discharge $(n=123)$ and PE occurring in-hospital $(n=29)$ versus post-discharge $(n=78)$

\begin{tabular}{|c|c|c|c|c|c|c|}
\hline \multirow[t]{2}{*}{ Predictors } & \multicolumn{3}{|c|}{ In-hospital DVT } & \multicolumn{3}{|c|}{ Post-discharge DVT } \\
\hline & OR & $95 \% \mathrm{CI}$ & $\mathrm{p}$ value & OR & $95 \% \mathrm{CI}$ & $\mathrm{p}$ value \\
\hline Age per 10 years increase & 1.28 & $1.06-1.55$ & 0.01 & 1.28 & $1.12-1.47$ & $<0.001$ \\
\hline BMI per $5 \mathrm{~kg} / \mathrm{m}^{2}$ increase & 1.23 & $1.01-1.46$ & $\mathbf{0 . 0 3}$ & 1.25 & $1.09-1.41$ & $<0.001$ \\
\hline Dependent functional status & 2.63 & $1.18-5.27$ & 0.01 & 0.82 & $0.34-1.68$ & 0.62 \\
\hline Preoperative $\mathrm{WBC}>12,000 / \mu \mathrm{L}$ & 1.76 & $1.00-2.97$ & 0.05 & 1.05 & $0.69-1.57$ & 0.80 \\
\hline Steroid usage & 1.38 & $0.71-2.52$ & 0.32 & 2.17 & $1.39-3.30$ & $<0.001$ \\
\hline Admission to operation $\geq 2$ days & 1.85 & $1.08-3.19$ & 0.02 & 2.02 & $1.37-2.98$ & $<0.001$ \\
\hline OR time per $60 \mathrm{~min}$ increase & 1.26 & $1.13-1.39$ & $<0.001$ & 1.04 & $0.94-1.15$ & 0.40 \\
\hline \multirow[t]{2}{*}{ Predictors } & \multicolumn{3}{|c|}{ In-hospital PE } & \multicolumn{3}{|c|}{ Post-discharge PE } \\
\hline & OR & $95 \% \mathrm{CI}$ & $\mathrm{p}$ value & $\overline{\mathrm{OR}}$ & $95 \% \mathrm{CI}$ & $\mathrm{p}$ value \\
\hline Age per 10 years increase & 1.08 & $0.84-1.41$ & 0.56 & 1.33 & $1.13-1.58$ & $<0.001$ \\
\hline Male gender & 0.93 & $0.43-2.04$ & 0.85 & 2.32 & $1.38-4.07$ & 0.002 \\
\hline BMI per $5 \mathrm{~kg} / \mathrm{m}^{2}$ increase & 1.27 & $0.97-1.62$ & 0.07 & 1.24 & $1.04-1.46$ & 0.01 \\
\hline Dependent functional status & 5.46 & $1.96-13.12$ & $<0.001$ & 2.15 & $0.94-4.31$ & 0.05 \\
\hline OR time per $60 \mathrm{~min}$ increase & 1.24 & $1.06-1.43$ & 0.004 & 1.10 & $0.98-1.23$ & 0.10 \\
\hline
\end{tabular}

Bold p-values below 0.05 were considered as statistically significant

$B M I$ body mass index, $D V T$ deep venous thrombosis, $O R$ operation room, $P E$ pulmonary embolism, $W B C$ white blood cell count

Table 3 Overview overall and specific risk factors for VTE

\begin{tabular}{|c|c|c|}
\hline \multicolumn{3}{|c|}{ Overall risk factors } \\
\hline \multicolumn{3}{|c|}{ Older age } \\
\hline \multicolumn{3}{|c|}{ Higher BMI } \\
\hline \multicolumn{3}{|c|}{ Specific risk factors } \\
\hline & In-hospital & Post-discharge \\
\hline DVT & $\begin{array}{l}\text { Admission } \geq 2 \text { days pre-op } \\
\text { Longer operative times } \\
\text { Dependent functional status }\end{array}$ & $\begin{array}{l}\text { Admission } \geq 2 \text { days pre-op } \\
\text { Steroid usage }\end{array}$ \\
\hline PE & $\begin{array}{l}\text { Longer operative times } \\
\text { Dependent functional status }\end{array}$ & Male gender \\
\hline
\end{tabular}

This study was underpowered to identify specific risk factors of inhospital PEs

$B M I$ body mass index, $D V T$ deep venous thrombosis, $P E$ pulmonary embolism, pre-op preoperatively

ASA-classification, hypertension, weight loss, bleeding disorders, preoperative sodium $<135 \mathrm{mEq} / \mathrm{L}$, and longer operative times were found to be predictors of postoperative ICH requiring surgical evacuation (Table 4).

\section{Discussion}

VTE is one of the most common major complications and reasons for readmission, and ICH the most common reason for reoperation among patients undergoing craniotomy
Table 4 Multivariable logistic regression analysis for ICH within 30 days after surgery $(n=72)$

\begin{tabular}{lllll}
\hline Predictor & Definition & \multicolumn{2}{l}{ ICH } & \\
\cline { 3 - 5 } & & OR & $95 \%$ CI & p value \\
\hline ASA classification & I-II & Ref & - & - \\
& III & 1.45 & $0.74-3.11$ & 0.31 \\
& IV-V & 3.23 & $1.50-7.59$ & $\mathbf{0 . 0 0 4}$ \\
Hypertension & & 2.27 & $1.38-3.75$ & $\mathbf{0 . 0 0 1}$ \\
Weight loss & & 4.42 & $1.48-10.67$ & $\mathbf{0 . 0 0 3}$ \\
Bleeding disorder & & 3.13 & $1.16-7.09$ & $\mathbf{0 . 0 1}$ \\
Preoperative SIRS & & 2.45 & $0.98-5.21$ & 0.05 \\
Preoperative sodium & $135-145$ & Ref & - & - \\
& $<135$ & 2.41 & $1.29-4.26$ & $\mathbf{0 . 0 0 4}$ \\
& $>145$ & 1.14 & $0.06-5.59$ & 0.90 \\
Operative time & Minutes & $1.20^{\mathrm{a}}$ & $1.07-1.33$ & $<\mathbf{0 . 0 0 1}$ \\
\hline
\end{tabular}

Bold p-values below 0.05 were considered as statistically significant ASA American Society of Anesthesiologists, CI confidence interval, SIRS systematic inflammatory response syndrome

${ }^{\mathrm{a}}$ Inflated $\beta$-coefficients to odds ratio per $60 \mathrm{~min}$ increase

for primary malignant brain tumors. This multicenter study provides novel and useful information regarding the timing of these events and identification of high-risk patients. The increased risk of VTE extends beyond the period of hospitalization, especially for PE, whereas ICH occurs predominantly within the first days after surgery. The VTE risk 
profile depends on the type of VTE (DVT vs. PE events) and the clinical setting (hospitalized vs. post-discharge patients).

The patient population in this study was technically classified as all those with primary malignant brain tumors based on ICD-9 codes. Gliomas represent close to $80 \%$ of primary malignant brain tumors [38], however, there is no standard ICD-9 code specific for glioma. The Central Brain Tumor Registry of the United States (CBTRUS) argues that multiple combinations of ICD histology codes can be used to define gliomas, and their approach was modeled in this study [38]. Therefore, these results are primarily applicable to glioma patients and should be put in the context of previous outcome research on glioma patients.

\section{Previous work}

Several multicenter studies have previously investigated the short-term incidence of and risk factors for VTE after brain tumor surgery [3, 13, 39-45], of which four studies focused on glioma patients $[3,13,39,41]$. From these studies, the rate of VTE following craniotomy is cited as $3.3-7.5 \%$ for glioma patients $[3,13,39,41]$ and $2.3-4.0 \%$ for brain tumors patients in general [11,40-42,44], with a follow-up ranging from solely the initial hospital stay to 6 weeks after surgery. The 30-day VTE rate was as high as $9.3 \%$ when asymptomatic DVTs were included too [3]. These results are comparable to the VTE rates found in the current study and suggest a higher rate of VTE in glioma patients postoperatively compared to other brain tumors.

Simanek et al. assessed the cumulative incidence of VTE over time after craniotomy for gliomas, demonstrating a major increase in the number of events in the first 3 months after surgery; however, no granular insight into the distribution of events within the first few weeks postoperatively was provided due to a low sample size. Neither did this study stratify for VTE type or the clinical setting of the patient [4].

Risk factors identified for VTE after craniotomy for gliomas are older age, history of craniotomy, history of VTE, coagulopathy, seizures, increased stay on the intensive care unit, prolonged hospital stay, residual tumor tissue, and absence of thromboprophylactic therapy [3, 4, 6, 12-15]. Missios et al. stratified for VTE type demonstrating different risk profiles for postoperative DVT and PE. Male gender, Hispanic ethnicity, and medium bed size were predictive for PE, whereas chronic heart failure was predictive for DVT [3]. Other predictors of postoperative VTE identified in the broader group of brain tumor patients were higher BMI, hypertension, functional dependence, lower Karnofsky Performance Scale (KPS) score, motor deficits, ventilator dependence, steroid usage, preoperative sepsis, longer operative times, and higher World Health Organization (WHO) tumor grade [11, 40, 42, 43, 46].
Prophylactic anticoagulation is a commonly used strategy to prevent VTE but should be carefully balanced against the risk of ICH. In previous studies, the rates of ICH following craniotomy for brain tumors is cited as $1.0-4.0 \%$ with a follow-up ranging between the initial hospital stay and longterm survival after surgery [6, 13-15, 44, 46-48]. However, definitions for major ICH varied between volumetric measurement of the hematoma, presence of symptoms, decrease in hemoglobin, or need for surgical evacuation of hematoma $[14,15,21,23,24,49]$.

Mantia et al. assessed the cumulative incidence of ICH over time after craniotomy for glioma. However, no timeto-event analysis was provided for the direct postoperative period due to a low sample size [23]. Neither did this study stratify for the clinical setting of the patient. Risk factors associated with ICH were history of craniotomy, use of bevacizumab, and therapeutic anticoagulation for VTE [13, 20-24]. The association between thromboprophylactic anticoagulation and ICH remains to be elucidated [15].

To our knowledge, the current study is the first large multicenter assessment including a descriptive time-to-event analysis for both VTE and ICH within 30 days after craniotomy for primary malignant brain tumors. Additionally, it is the first study that uses the NSQIP database to identify predictors of ICH after brain tumor resection. By addressing thrombotic outcomes as well as hemorrhagic outcomes, this study provides a meaningful direction for future research on thromboprophylactic treatment strategies. Lastly, the large sample size allows a stratification of both the descriptive and inferential analysis, demonstrating differences in risk profile and incidence over time based on VTE type (DVT vs. PE) and clinical setting (hospitalized vs. post-discharge patients).

\section{Limitations}

Complication rates found in the current study can be conservative estimates if events were not reported back to the hospitals. VTEs were only coded as events if they were diagnosed and treated, thereby missing asymptomatic and undetected VTEs. The database additionally lacks several demographic variables identified in other studies as predictors. Tumor specific information (histology, size, location, residual tumor volume) and complication specific information (location and classification of DVT, PE, and ICH) was not available. However, both VTE and ICH were defined in the NSQIP database as complications requiring medical and surgical treatment, respectively, resulting in selection of the most clinically relevant events. Perhaps most importantly, no data is available regarding anticoagulation status and nonpharmaceutical prophylactic methods. Therefore, this study offers limited insight in the efficacy of different thromboprophylactic treatment strategies and their association with the occurrence of ICH. Selection bias can be introduced since 
institutions can selectively contribute patients to the NSQIP registry. There was a lower number of events due to separate analyses based on VTE type and clinical setting; however, our study was not underpowered for most outcome measures according to rule of 10 events per variable in the multivariable analysis [50]. Lastly, VTE and ICH events after the 30-day time period established in NSQIP are not accounted for in this study, although studies have demonstrated that the risk of VTE events remains non-negligible beyond 30 days postoperatively with incidences up to $26 \%$ in the first 12 months postoperatively [4-6]. Despite these limitations, this study provides useful insight into the rates, timing, and predictors of DVT, PE, and ICH after craniotomy for primary malignant brain tumors. Due to the multicenter nature of the NSQIP dataset, the results of this study may be more representative of typical management at all hospitals, including but not limited to tertiary care academic centers.

\section{Implications}

The significant prevalence of VTE and ICH following craniotomy for primary malignant brain tumors found in the current study indicates that there is still room for improvement when it comes to monitoring and preventing these events. Rolston et al. demonstrated that the prevalence of VTE following a neurosurgical procedure registered in NSQIP has remained consistent over the last years [51]. This suggests that perioperative management still hasn't improved effectively with regards to preventing VTE, despite the attention it receives in neurosurgical literature.

These results particularly encourage the need for continued awareness for VTE post-discharge, especially for PE, which has more lethal consequences. These PEs can also be considered more sudden since they were less often preceded by a known DVT. PEs preceded by a DVT, however, suggest inadequate treatment for the initial VTE event. It is possible that DVTs are less frequent post-discharge. It is our primary suspicion, however, that DVTs are underdetected after leaving the hospital because they are less frequently symptomatic and cannot be effectively screened for. It is also possible that patients develop symptomatic DVTs but are unaware of the signs and symptoms until they progress to PE, implicating a possible role for improved patient education in preventing morbidity caused by DVT and PE. In prospective randomized control trials investigating different VTE prophylaxis modalities, Goldhaber et al. screened all craniotomy patients prior to discharge and found $9.3 \%$ of patients to have VTE, most of which were asymptomatic in both studies [45].

Most guidelines recommend that prophylactic use of low-molecular weight heparin or unfractionated heparin should be considered in all cancer patients undergoing major surgery [16-19]. In patients undergoing operations for brain tumors, however, the benefits of anticoagulation should be carefully balanced against the risk of ICH [52, 53]. Although most guidelines support the use of pharmacological prophylaxis in patients with brain tumors, proper timing of prophylaxis remains controversial and the use of anticoagulation often depends on the surgeon's preference [52-54]. Recommendations vary between administration throughout hospitalization [19], up to 7-10 days after surgery $[16,17,55]$, until the patient is mobile [52], or timing based on the individual risk profile [56]. A lack of scientific evidence is primarily the cause of this variation in recommendations. Recent systematic reviews and meta-analyses of VTE prophylaxis in patients undergoing craniotomy for brain tumors have been performed [42, 57-60]. These analyses have compared different VTE prophylaxis modalities, as well as their safety and cost effectiveness, but they do not thoroughly investigate the efficacy of prophylaxis over time to determine a recommended duration. Only one clinical trial studied the effect of continued prophylaxis up to 12 months after surgery [15]. No significant association was found between prolonged prophylaxis and the rate of both VTE and ICH; however, the trial was stopped early because of expiration of study medication, and the control group received placebo instead of short-term prophylaxis. Many patients may not need or benefit from continuing thromboprophylactic therapy beyond discharge. Algattas et al. reviewed the safety and effectiveness of thromboprophylactic strategies and indicated that different regimens may have different efficacies depending on the patient's VTE risk profile [57]. This highlights the importance of using the appropriate risk profile for optimizing postoperative management.

Since the NSQIP data does not contain information on thromboprophylactic strategies, the current study provides limited insight into the efficacy or safety of prophylactic anticoagulation and insufficient evidence to change the current clinical practice of thromboprophylaxis in patients undergoing operations for primary malignant brain tumors. Therefore, we concur with the current guidelines that recommend pharmaceutic prophylaxis (low-molecular weight heparin or unfractionated heparin) in combination with mechanical prophylaxis (anti-embolism stockings or intermittent pneumatic compression devices) postoperatively until the end of hospitalization or until the patient is mobile. Absolute contra-indications for these include recent ICH or another active major bleeding [16-19, 52, 53, 55, 56].

\section{Suggestions for future research}

Despite its limitations, this study provides useful insight into the prevalence, timing, and risk factors of postoperative VTE and ICH after craniotomy for primary malignant brain tumors. The results of the current study demonstrate that there is still room for improvement, especially with regard to 
the prevention of PE after hospitalization. The distinct critical time periods for both thrombotic and hemorrhagic events suggest a potentially safe and effective role for continuing prophylactic anticoagulation post-discharge in high-risk patients. Additionally, the typical patient at risk for developing a VTE during hospitalization is not the same as the typical patient at risk for developing a VTE post-discharge. This is crucial for tailoring post-discharge management to the risk profile of the individual patient and suggests an important direction for future research. Therefore, future research should study the effects of timing of thromboprophylactic therapy, screening for asymptomatic events, and the effects of patient education on the occurrence of VTE and/or ICH. Additionally, future studies should construct prediction models for DVT, PE, and ICH and examine the effectiveness of tailoring postoperative thromboprophylaxis to the individual risk profile of patients undergoing craniotomy for primary malignant brain tumors.

\section{Conclusion}

The increased risk of VTE experienced by patients with primary malignant brain tumors extends beyond the period of hospitalization, especially for PE, whereas ICH occurs predominantly in the first few days after surgery. The risk profile for VTE depends on the type of VTE and the clinical setting of the patient. VTE can have fatal consequences if not recognized early, therefore clinicians should have high suspicion during the postoperative period and a low threshold for specific monitoring and prevention.

Funding National Institutes of Health (NIH) Training Grant T32 CA 009001 (DJC).

\section{Compliance with ethical standards}

Conflict of interest J.T.S., N.H.G., D.J.C., I.S.M., H.H.D., F.Y.F.L.V., T.R.S., M.L.B., Nothing to Disclose. W.B.G. Codman, Coviden Proctor, Consultant.

Open Access This article is distributed under the terms of the Creative Commons Attribution 4.0 International License (http://creativecommons.org/licenses/by/4.0/), which permits unrestricted use, distribution, and reproduction in any medium, provided you give appropriate credit to the original author(s) and the source, provide a link to the Creative Commons license, and indicate if changes were made.

\section{References}

1. Fadul C, Wood J, Thaler H, Galicich J, Patterson RH Jr, Posner JB (1988) Morbidity and mortality of craniotomy for excision of supratentorial gliomas. Neurology 38:1374-1379
2. Marcus LP, McCutcheon BA, Noorbakhsh A, Parina RP, Gonda DD, Chen C, Chang DC, Carter BS (2014) Incidence and predictors of 30-day readmission for patients discharged home after craniotomy for malignant supratentorial tumors in California (1995-2010). J Neurosurg 120:1201-1211. doi:10.3171/2014.1 .JNS131264

3. Missios S, Kalakoti P, Nanda A, Bekelis K (2015) Craniotomy for glioma resection: a predictive model. World Neurosurg 83:957964. doi:10.1016/j.wneu.2015.04.052

4. Simanek R, Vormittag R, Hassler M, Roessler K, Schwarz M, Zielinski C, Pabinger I, Marosi C (2007) Venous thromboembolism and survival in patients with high-grade glioma. Neuro Oncol 9:89-95. doi:10.1215/15228517-2006-035

5. Streiff MB, Ye X, Kickler TS, Desideri S, Jani J, Fisher J, Grossman SA (2015) A prospective multicenter study of venous thromboembolism in patients with newly-diagnosed high-grade glioma: hazard rate and risk factors. J Neurooncol 124:299-305. doi:10.1007/s11060-015-1840-z

6. Smith TR, Lall RR, Graham RB, McClendon J Jr, Lall RR, Nanney AD, Adel JG, Zakarija A, Chandler JP (2014) Venous thromboembolism in high grade glioma among surgical patients: results from a single center over a 10 year period. J Neurooncol 120:347-352. doi:10.1007/s11060-014-1557-4

7. Khalil J, Bensaid B, Elkacemi H, Afif M, Bensaid Y, Kebdani T, Benjaafar N (2015) Venous thromboembolism in cancer patients: an underestimated major health problem. World J Surg Oncol 13:204. doi:10.1186/s12957-015-0592-8

8. Sartori MT, Della Puppa A, Ballin A, Saggiorato G, Bernardi D, Padoan A, Scienza R, d'Avella D, Cella G (2011) Prothrombotic state in glioblastoma multiforme: an evaluation of the procoagulant activity of circulating microparticles. J Neurooncol 104:225231. doi:10.1007/s11060-010-0462-8

9. Cote DJ, Smith TR (2016) Venous thromboembolism in brain tumor patients. J Clin Neurosci 25:13-18. doi:10.1016/j. jocn.2015.05.053

10. Stein PD, Beemath A, Meyers FA, Skaf E, Sanchez J, Olson RE (2006) Incidence of venous thromboembolism in patients hospitalized with cancer. Am J Med 119:60-68. doi:10.1016/j. amjmed.2005.06.058

11. Kimmell KT, Walter KA (2014) Risk factors for venous thromboembolism in patients undergoing craniotomy for neoplastic disease. J Neurooncol 120:567-573. doi:10.1007/s11060-014-1587-y

12. Edwin NC, Khoury MN, Sohal D, McCrae KR, Ahluwalia MS, Khorana AA (2016) Recurrent venous thromboembolism in glioblastoma. Thromb Res 137:184-188. doi:10.1016/j. thromres.2015.11.027

13. Chang SM, Parney IF, McDermott M, Barker FG 2nd, Schmidt MH, Huang W, Laws ER Jr, Lillehei KO, Bernstein M, Brem H, Sloan AE, Berger M, Glioma Outcomes I (2003) Perioperative complications and neurological outcomes of first and second craniotomies among patients enrolled in the Glioma Outcome Project. J Neurosurg 98:1175-1181. doi:10.3171/jns.2003.98.6.1175

14. Perry SL, Bohlin C, Reardon DA, Desjardins A, Friedman AH, Friedman HS, Vredenburgh JJ (2009) Tinzaparin prophylaxis against venous thromboembolic complications in brain tumor patients. J Neurooncol 95:129-134. doi:10.1007/ s11060-009-9911-7

15. Perry JR, Julian JA, Laperriere NJ, Geerts W, Agnelli G, Rogers LR, Malkin MG, Sawaya R, Baker R, Falanga A, Parpia S, Finch T, Levine MN (2010) PRODIGE: a randomized placebo-controlled trial of dalteparin low-molecular-weight heparin thromboprophylaxis in patients with newly diagnosed malignant glioma. J Thromb Haemost 8:1959-1965. doi:10.1111/j.1538-7836.2010.03973.x

16. Farge D, Bounameaux H, Brenner B, Cajfinger F, Debourdeau P, Khorana AA, Pabinger I, Solymoss S, Douketis J, Kakkar A 
(2016) International clinical practice guidelines including guidance for direct oral anticoagulants in the treatment and prophylaxis of venous thromboembolism in patients with cancer. Lancet Oncol 17:e452-e466. doi:10.1016/S1470-2045(16)30369-2

17. Farge D, Debourdeau P, Beckers M, Baglin C, Bauersachs RM, Brenner B, Brilhante D, Falanga A, Gerotzafias GT, Haim N, Kakkar AK, Khorana AA, Lecumberri R, Mandala M, Marty M, Monreal M, Mousa SA, Noble S, Pabinger I, Prandoni P, Prins MH, Qari MH, Streiff MB, Syrigos K, Bounameaux H, Buller HR (2013) International clinical practice guidelines for the treatment and prophylaxis of venous thromboembolism in patients with cancer. J Thromb Haemost 11:56-70. doi:10.1111/jth.12070

18. Lyman GH, Bohlke K, Falanga A, American Society of Clinical Oncology (2015) Venous thromboembolism prophylaxis and treatment in patients with cancer: American Society of Clinical Oncology clinical practice guideline update. J Oncol Pract 11:e442-444. doi:10.1200/JOP.2015.004473

19. Streiff MB (2014) NCCN Clinical Practice Guidelines in Oncology (NCCN Guidelines ${ }^{\circledR}$ ). Cancer-Associated Venous Thromboembolic Disease. Version 1.2014. National Comprehensive Cancer Network

20. Zwicker JI, Karp Leaf R, Carrier M (2016) A meta-analysis of intracranial hemorrhage in patients with brain tumors receiving therapeutic anticoagulation. J Thromb Haemost 14:1736-1740. doi: $10.1111 /$ jth. 13387

21. Nghiemphu P, Green RM, Pope WB, Lai A, Cloughesy TF (2008) Safety of anticoagulation use and bevacizumab in patients with glioma. Neuro-Oncology 10:355-360. doi:10.1215/15228517-2008-009

22. Nabi S, Kahlon P, Bozorgnia F, Arshad A, Mikkelsen T, Donthireddy V (2016) Predictors of venous thromboembolism in patients with glioblastoma. Pathol Oncol Res 22:311-316. doi:10.1007/s12253-015-0008-7

23. Mantia C, Uhlmann EJ, Puligandla M, Weber GM, Neuberg D, Zwicker JI (2017) Predicting the higher rate of intracranial hemorrhage in glioma patients receiving therapeutic enoxaparin. Blood. doi:10.1182/blood-2017-02-767285

24. Al Megren M, De Wit C, Al Qahtani M, Le Gal G, Carrier M (2017) Management of venous thromboembolism in patients with glioma. Thromb Res 156:105-108. doi:10.1016/j. thromres.2017.06.010

25. Lieber BA, Appelboom G, Taylor BE, Malone H, Agarwal N, Connolly ES Jr (2015) Assessment of the "July Effect": outcomes after early resident transition in adult neurosurgery. $\mathrm{J}$ Neurosurg. doi:10.3171/2015.4.jns 142149

26. McGirt MJ, Godil SS, Asher AL, Parker SL, Devin CJ (2015) Quality analysis of anterior cervical discectomy and fusion in the outpatient versus inpatient setting: analysis of 7288 patients from the NSQIP database. Neurosurg Focus 39:E9. doi:10.317 1/2015.9.focus 15335

27. Lieber BA, Appelboom G, Taylor BE, Lowy FD, Bruce EM, Sonabend AM, Kellner C, Connolly ES Jr, Bruce JN (2015) Preoperative chemotherapy and corticosteroids: independent predictors of cranial surgical-site infections. J Neurosurg. doi: 10.3171/2015.4.jns 142719

28. Lim S, Parsa AT, Kim BD, Rosenow JM, Kim JY (2015) Impact of resident involvement in neurosurgery: an analysis of 8748 patients from the 2011 American College of Surgeons National Surgical Quality Improvement Program database. J Neurosurg 122:962-970. doi:10.3171/2014.11.jns 1494

29. McCutcheon BA, Ciacci JD, Marcus LP, Noorbakhsh A, Gonda DD, McCafferty R, Taylor W, Chen CC, Carter BS, Chang DC (2015) Thirty-day perioperative outcomes in spinal fusion by specialty within the NSQIP Database. Spine 40:1122-1131. doi:10.1097/brs.0000000000000599
30. Dasenbrock HH, Devine CA, Liu KX, Gormley WB, Claus EB, Smith TR, Dunn IF (2016) Thrombocytopenia and craniotomy for tumor: a National Surgical Quality Improvement Program analysis. Cancer. doi:10.1002/cncr.29984

31. Lieber BA, Han J, Appelboom G, Taylor BE, Han B, Agarwal N, Connolly ES Jr (2016) Association of steroid use with deep venous thrombosis and pulmonary embolism in neurosurgical patients: A National Database analysis. World Neurosurg. doi:10.1016/j.wneu.2016.01.033

32. Kim BD, Smith TR, Lim S, Cybulski GR, Kim JY (2014) Predictors of unplanned readmission in patients undergoing lumbar decompression: multi-institutional analysis of 7016 patients. J Neurosurg Spine 20:606-616. doi:10.3171/2014.3.spine13699

33. Dasenbrock HH, Liu KX, Devine CA, Chavakula V, Smith TR, Gormley WB, Dunn IF (2015) Length of hospital stay after craniotomy for tumor: a National Surgical Quality Improvement Program analysis. Neurosurg Focus 39:E12. doi:10.3171/2015.10.focus 15386

34. Sellers MM, Merkow RP, Halverson A, Hinami K, Kelz RR, Bentrem DJ, Bilimoria KY (2013) Validation of new readmission data in the American College of Surgeons National Surgical Quality Improvement Program. J Am Coll Surg 216:420 427. doi:10.1016/j.jamcollsurg.2012.11.013

35. Hackett NJ, De Oliveira GS, Jain UK, Kim JY (2015) ASA class is a reliable independent predictor of medical complications and mortality following surgery. Int J Surg 18:184-190. doi:10.1016/j.ijsu.2015.04.079

36. Abt NB, De la Garza-Ramos R, Olorundare IO, McCutcheon BA, Bydon A, Fogelson J, Nassr A, Bydon M (2016) Thirty day postoperative outcomes following anterior lumbar interbody fusion using the National Surgical Quality Improvement Program database. Clin Neurol Neurosurg 143:126-131. doi:10.1016/j.clineuro.2016.02.024

37. Lukasiewicz AM, Grant RA, Basques BA, Webb ML, Samuel AM, Grauer JN (2016) Patient factors associated with 30-day morbidity, mortality, and length of stay after surgery for subdural hematoma: a study of the American College of Surgeons National Surgical Quality Improvement Program. J Neurosurg 124:760-766. doi:10.3171/2015.2.jns142721

38. Ostrom QT, Gittleman H, Xu J, Kromer C, Wolinski Y, Kruchko C, Barnholtz-Sloan JS (2016) CBTRUS Statistical Report: Primary brain and other central nervous system tumors diganosed int he United States in 2009-2013. Neuro-Oncology 18:v1-v75. doi:10.1093/neuonc/now207

39. Auguste KI, Quinones-Hinojosa A, Gadkary C, Zada G, Lamborn KR, Berger MS (2003) Incidence of venous thromboembolism in patients undergoing craniotomy and motor mapping for glioma without intraoperative mechanical prophylaxis to the contralateral leg. J Neurosurg 99:680-684. doi:10.3171/jns.2003.99.4.0680

40. Chaichana KL, Pendleton C, Jackson C, Martinez-Gutierrez JC, Diaz-Stransky A, Aguayo J, Olivi A, Weingart J, Gallia G, Lim M, Brem H (2013) Deep venous thrombosis and pulmonary embolisms in adult patients undergoing craniotomy for brain tumors. Neurol Res 35:206-211. doi:10.1179/1743132812y.0000000126

41. Chan AT, Atiemo A, Diran LK, Licholai GP, McLaren M, Black PM, Creager MA, Goldhaber SZ (1999) Venous thromboembolism occurs frequently in patients undergoing brain tumor surgery despite prophylaxis. J Thromb Thrombolysis 8:139-142

42. Cote DJ, Dubois HM, Karhade AV, Smith TR (2016) Venous thromboembolism in patients undergoing craniotomy for brain tumors: A U.S. Nationwide Analysis. Semin Thromb Hemost 42:870-876. doi:10.1055/s-0036-1592306

43. Dasenbrock HH, Liu KX, Chavakula V, Devine CA, Gormley WB, Claus EB, Smith TR, Dunn IF (2017) Body habitus, serum albumin, and the outcomes after craniotomy for tumor: a National 
Surgical Quality Improvement Program analysis. J Neurosurg 126:677-689. doi:10.3171/2016.2.jns 152345

44. Nuno M, Carico C, Mukherjee D, Ly D, Ortega A, Black KL, Patil CG (2015) Association between in-hospital adverse events and mortality for patients with brain tumors. J Neurosurg 123:12471255. doi:10.3171/2014.10.jns 141516

45. Goldhaber SZ, Dunn K, Gerhard-Herman M, Park JK, Black PM (2002) Low rate of venous thromboembolism after craniotomy for brain tumor using multimodality prophylaxis. Chest 122:1933-1937

46. Smith TR, Nanney AD 3rd, Lall RR, Graham RB, McClendon J Jr, Lall RR, Adel JG, Zakarija A, Cote DJ, Chandler JP (2015) Development of venous thromboembolism (VTE) in patients undergoing surgery for brain tumors: results from a single center over a 10 year period. J Clin Neurosci 22(3):519-525. doi:10.1016/j. jocn.2014.10.003

47. Portillo J, de la Rocha IV, Font L, Braester A, Madridano O, Peromingo JA, Apollonio A, Pagan B, Bascunana J, Monreal M (2015) Venous thromboembolism in patients with glioblastoma multiforme: findings of the RIETE registry. Thromb Res 136:1199-1203. doi:10.1016/j.thromres.2015.10.043

48. Pan E, Tsai JS, Mitchell SB (2009) Retrospective study of venous thromboembolic and intracerebral hemorrhagic events in glioblastoma patients. Anticancer Res 29:4309-4313

49. Auer TA, Renovanz M, Marini F, Brockmann MA, Tanyildizi Y (2017) Ischemic stroke and intracranial hemorrhage in patients with recurrent glioblastoma multiforme, treated with bevacizumab. J Neurooncol. doi:10.1007/s11060-017-2467-z

50. Peduzzi P, Concato J, Kemper E, Holford TR, Feinstein AR (1996) A simulation study of the number of events per variable in logistic regression analysis. J Clin Epidemiol 49:1373-1379

51. Rolston JD, Han SJ, Bloch O, Parsa AT (2014) What clinical factors predict the incidence of deep venous thrombosis and pulmonary embolism in neurosurgical patients? J Neurosurg 121:908918. doi:10.3171/2014.6.JNS131419

52. Strangman D (2009) Clinical Practice Guidelines for the management of adult gliomas: astrocytomas and oligodendrogliomas. Cancer Council Australia/Australian Cancer Network/Clinical Oncological Society of Australia

53. Guyatt GH, Akl EA, Crowther M, Gutterman DD, Schuunemann HJ, American College of Chest Physicians Antithrombotic
T, Prevention of Thrombosis P (2012) Executive summary: Antithrombotic Therapy and Prevention of Thrombosis. 9th edn: American College of Chest Physicians Evidence-Based Clinical Practice Guidelines. Chest 141:7S-47S. doi:10.1378/chest.1412S3

54. Carman TL, Kanner AA, Barnett GH, Deitcher SR (2003) Prevention of thromboembolism after neurosurgery for brain and spinal tumors. South Med J 96:17-22. doi:10.1097/01. SMJ.0000047628.44490.B2

55. Lyman GH, Bohlke K, Khorana AA, Kuderer NM, Lee AY, Arcelus JI, Balaban EP, Clarke JM, Flowers CR, Francis CW, Gates LE, Kakkar AK, Key NS, Levine MN, Liebman HA, Tempero MA, Wong SL, Somerfield MR, Falanga A, American Society of Clinical O (2015) Venous thromboembolism prophylaxis and treatment in patients with cancer: American Society Of Clinical Oncology clinical practice guideline update 2014. J Clin Oncol 33:654-656. doi:10.1200/JCO.2014.59.7351

56. Prevention and treatment of venous thromboembolism (2013) International Consensus Statement 2013 Guidelines According to Scientific Evidence/Cardiovascular Disease Educational and Research Trust (UK)/European Venous Forum/North American Thrombosis Forum International Union of Angiology and Union Internationale du Phlebologie

57. Algattas H, Damania D, DeAndrea-Lazarus I, Kimmell KT, Marko NF, Walter KA, Vates GE, Jahromi BS (2017) Systematic review of safety and cost-effectiveness of venous thromboembolism prophylaxis strategies in patients undergoing craniotomy for brain tumor. Neurosurgery. doi:10.1093/neuros/nyx 156

58. Alshehri N, Cote DJ, Hulou MM, Alghamdi A, Alshahrani A, Mekary RA, Smith TR (2016) Venous thromboembolism prophylaxis in brain tumor patients undergoing craniotomy: a meta-analysis. J Neurooncol 130:561-570. doi:10.1007/s11060-016-2259-x

59. Cote DJ, Dawood HY, Smith TR (2016) Venous thromboembolism in patients with high-grade glioma. Semin Thromb Hemost 42:877-883. doi:10.1055/s-0036-1592334

60. Salmaggi A, Simonetti G, Trevisan E, Beecher D, Carapella CM, DiMeco F, Conti L, Pace A, Filippini G (2013) Perioperative thromboprophylaxis in patients with craniotomy for brain tumours: a systematic review. J Neurooncol 113:293-303. doi:10.1007/s11060-013-1115-5 